\title{
Graphic Design as Means of Students' Creative Activity
}

\author{
Ayad Hayawi Al Atabi and Luhaib Kamil Al Abboodi
}

\begin{abstract}
The article encloses issues of teaching graphic design to students as a specific type of creative project activity. The paper examines the essence of graphic design from the viewpoint of teaching Arts students and discloses educational conditions for the effective graphic design teaching and learning processes. The study seeks to understand what factors condition effectiveness in students aesthetic and artistic-graphic education.
\end{abstract}

Index Terms - Creative and project activity, graphic design, sociocultural activity, web design.

\section{INTRODUCTION}

Nowadays graphic design appears a crucial constituent of design education. Performing an interdisciplinary function it serves as a link between professional, psychological and pedagogical knowledge and skills. It also is a universal form of comprehending surrounding environment from the view of aesthetic and functional reasonability.

Graphic design as a specific kind of creative and project activity is thoroughly examined in the investigations of $\mathrm{A}$. Bohomolov, H. Brenkova, O. Henisaretsky, J. Ladyhin, R. Muhutdinov, N. Postnikov, S. Serov, V. Sidorenko, S. Khan-Mahomedov, J. Chernievich who outlined its structure and main characteristics.

This kind of design aims at developing and problem education, most broadly reflecting possibilities of complex approach to the issue of developing education (L. Vygotsky, V. Davydov, A. Disterverg, L. Zankov, A. Leontiev, D. Elkonin), as well as teaching the basis of graphic and visual art activity of students and their aesthetic development in modern conditions.

In the area of visual perception of visual thinking, among international surveys, works of R. Arnheim, U. Boumen, N. George, H. Zemper, K. Kimur, N. Clark, G. Ovink, E. Rouder, P. Redmond and G. Wolker are of paramount importance.

\section{RESULTS AND DISCUSSION}

Graphic design represents a specific field of artistic project activity that is directed to create visual messages distributed via mass media communication means. [1] The definition of graphic design implies that it is a synthetic artistic creative activity directed to perceive and reflect the visual structures of the modern world [1].

Manuscript received December 15, 2013; revised January 23, 2014.

A. H. Al Atabi was with the South Ukrainian K.D. Ushynsky National Pedagogical University, Odessa 65020 Ukraine. He is now with Thi Qar University, Al Nasiriya 64001 Iraq (e-mail: ayad3hayawi@gmail.com).

L. K. Al Abboodi is with the Fine Arts Devision, the Ministry of Education of Iraq, 64001 Iraq (e-mail: laheeb_k76@yahoo.com).
The specificity of graphic is connected with its technological and artistic visual peculiarities - conditionality, efficiency, accessibility, duplicability and some other traditionally existing and recently emerging technologies laser and computer graphic, holography.

Concerning graphic design - it was among the first types of design. The inception of graphic design was conditioned upon the substratum of the creations of visualists, draftsmen, typographers, illustrators, retouchers and other distinguished skillful professionals in various fields who worked with the technical and visual aspects of design [2].

Conducting research we firstly defined the main tasks aiming at students' comprehension of graphic design fundamentals, like the following: to develop integral design thinking, imagination, creative capacities in the sociocultural aspect ("comfort, benefit, beauty") on the basis of aesthetic-functional perception and reflection of objects and phenomena; to form skills in accomplishing graphic and three-dimensional projects.

With the consideration of the fact that graphic design is represented by the activity with vividly expressed practicability (convenience in usage and perception, laconism, information value, aesthetic reasonability) the functional graphic design orientation is seen in modelling, projecting and creating aesthetic-functional elements and objects of the artificial environment (postcards, business cards, book covers, city prototypes), visualization of information (readability, general accessibility, laconism) with the usage of traditional and modern technologies and tools - pen, pencil, brush, coal.

From the viewpoint of psychology, in the process of graphic design education, two interconnected sides of psychic reality establish - mastering educational knowledge within separate block on one hand and personality development on the other hand.

Graphic design grounding on artistic creativity and systematic development allows building integration of different kinds of art, science and practice. It solves the issue of search skills formation and therefore broadens horizons of new vision, integration, enables teaching of purposeful moving from intention and concept to its realization in all spheres of activities. Design can be called a way of communication among all impacts of multiple arts, a means of objectifying creative concepts.

The established tasks and their realization secures wholeness of the education processes at the tertiary level with the account of every student's individuality.

In the process of teaching graphic design fundamentals the development of students' creativity occurs. It happens because the novelty of problematic situations preserves its objective character while changing only the area of its disclosure and has practical orientation.

Teaching students graphic design develops their overall 
professional artistic culture, the inner mechanism of which lies in aesthetic cognition, in the system of aesthetic relation with various objects of the environment through the mechanism of perception, experiencing, evaluating, taste. Graphic design education reveals the possibilities of personality`s adequate orientation in the many-sided system of aesthetic, visual and artistic values, appropriate motivation, development of visual thinking, formation of visual effect analysis skills, particularly those of structuring and combining outer phenomenal and inner content characteristics.

Graphic design as means of creative activity is dependent on students' compositional culture which is an active component of educational process and appears as a model of transforming world outlooks and professional vies into the picture of the world creatively expressed in artistic visual images with the aim of reaching higher ways of living organization. Compositional culture is a universal characteristic of a professional designer who is in the process of constant growth and examining professional puzzles via comprehending universal laws of harmonizing work, in self-improvement as a master. The content of compositional culture opens as $\mathrm{s}$ harmonious system of individual and professional sublimations of a specialist and represents specific projecting of general culture on a sphere of personal creativity. This complex inner quality of student's personality comprises value-motivational, cognitive, actional-practical, and emotional-evaluative components.

The constellation of knowledge and experience in realizing creative activity form students` artistic culture. The ways of developing this culture, including graphic culture, are numerous: there exist such popular approaches to doing it, as systematic, culturological, synergetic and competency-related. Therefore, modern state of education allows implementing differential approach to artistic and graphic design education. This contributes to the development of personal growth, self-cognition, spiritual realization and self-evaluation by students` of themselves.

The process of students`creative activity and artistic culture formation via graphic design occurs in stages and under the influence of demographic, social and socio-psychological factors. It involves mechanisms of both spontaneous and conscious character that are generally defined by the communication surroundings and conditions of individuals`activity, as well as their aesthetic parameters. The level of artistic culture also depends on the level of artistic education, scope of interests in the sphere of professional activity, depth of understanding and developed adequate evaluation of artistic virtues of the works.

All of these features are also concentrated in artistic taste which is a significant quality of personality formed and developed in the process of 'communicating' with the art. Artistic taste in its unique and individual development is not only aesthetic evaluation of the work, but involves emotional and sensual perception of the object in the state of aesthetic possession of it. Due to such a state the creative activity of a personality is enriched, the horizons of sensing and understanding surrounding phenomena are broadened, the comprehension of the purpose of one's existence and understanding the uniqueness of life becomes deeper.
The central matter in the artistic activity of a designer is creating an artwork. Here artistic cognition and artistic evaluation of the world takes place; a new artistic reality is getting created. Perception and comprehension of the artworks as those possessing artistic value is an analogue activity as their creation itself. Without personal activity, creative imagination, participation and co-feeling of a human understanding the artwork, without his or her visual thinking, the graphic artwork would remain a meaningless 'piece of something'. Hence, artistic creative activity is a sophisticated multi-componential and many-functional dynamic developing phenomenon with its vivid creative character, because the materialized result of this activity is a graphic artwork. An artwork is integrity of logical and visual, of emotional and rational, material and spiritual, theoretical and practical; in the process of its creation a person develops one's creative abilities: originality, individual expression of feelings and relations, sensitivity to special manifestation of others` artistic activity, ability of leading artistic dialogue. Artistic graphic activity is based on the principles of creativity: figurativeness, associativity, emotionality, metaphority.

Grounded on the qualities and paramount features of artworks, creative activity in graphic design is characterized by: artistic and aesthetic orientation of the artwork creator; idea and intention; sociocultural value of activity; favourable conditions for creativity; personal background (special abilities and psychological qualities); result. In the most generalized perspective such creative activity has these substructures: professional artistic, investigative, socio-cultural, artistic visual.

Formation of professional cultural thing, purpose-oriented development of abilities and artistic culture formation seriously impact graphic design education of students. Graphic activity is a result of artistic development, it provides the keys to understanding the processes of professional artistic culture formation. The specificity of graphic art lies in its simplicity and accessibility, as well as potential opportunity to possess the original product. It represents the process and result of any image with different means, materials and instruments. It is often used in various subjects and courses of study. Organized preparation at universities allows students to develop the necessary technique and language of graphic images, and graphic itself becomes an instrument of cognition and reflection of life, a means of educating creative abilities, personal self-realization in artistic creativity. As a fundamental area of artistic education graphic possesses integral character what is of paramount importance for preparing students for creative artistic activity.

Graphic creative activity covers areas of education involving the following:

1) Development of artistic taste (as a psychological mechanism of adequate artworks perception);

2) Formation of artistic consciousness (outlooks, cognitions, ideals);

3) Artistic education (broadening knowledge in the sphere of psychology, theory and history of art, aesthetics and other practically oriented disciplines).

In graphic design the most applicable and suitable 
approach of study is actional, which is based on the interpretation of culture as means of people`s activity and personality development.

Graphic activity in the framework of students art education is based on consecutive accomplishment of learning tasks by students with the purpose of acquiring the fundamental theoretical and practical knowledge and skills. It is represented as an integral didactic system based on creative approach in the process of working on the topic. Graphic activity creates conditions for interaction, integration of artistic, psychological and technological disciplines, and secures the opportunity to accomplish tasks most skillfully.

In order to successfully develop graphic creative activity of students in the context of art education at universities such mandatory constituents should be included:

1) The system of value orientations of personality, that is of feelings and experiencing values of professional artistc culture which define person`s attitude to the surrounding cultural reality and reflecting social experience of emotional-value attitude to reality;

2) The concrete methodology of the system of education and methods of its implementation in opening and grounding its content, that is the following elements: basic terms and notions without which acquiring knowledge would be difficult; scientific facts without awareness of which it is impossible to understand the patterns of education system functioning; regulations and objective relations between collective and individual artistic activity; system of scientific knowledge about art and principles of its development; the knowledge about methods of art cognition; leading trends of culture development which have general human value and define the content of art education.

Graphic activity broadens students` knowledge and skills in drawing, composition and painting, make the think of its practical implementation. The growth of professional level of graphic activity provides effective conditions for forming creative capacities of future specialists. Creative approach to making graphic works is based on concrete impressions, the result of which can be inspiration, freedom, new intentions necessary for future creative work of a designer.

Graphic is an ideal art 'material' for improving compositional mastery, colour perception culture, artistic taste, sense for space and form.

Nowadays graphic culture is a dominant form of culture itself. It embraces many unlike cultural phenomena (film, conceptual art, image, photography, painting, other fine arts, theatre, videoart, advertisement, commercials, web-design, videogames, graffiti, etc.) and involves media culture and screen art, development of emotional attitude to plastic arts, communication with using graphic channel touching any aspect of culture. The result of graphic culture acquisiting is abilities of visual images, capability of analyzing and interpreting them, contrasting, presenting, creating art images.

Teaching the fundamentals of graphic design is also technological, as it connects all the knowledge received earlier and transforms it into the complete real design-object, accomplished by the students and in demand of the modern time and society. The principal in students' education is tendency to develop cognitive processes, autonomy in fulfilling creative works (visual, artistic-graphic, three-dimensional, plastic, computer).

Design activity in the modern world is many-subject. The subject or the creator of the design as sociocultural activity, of projecting sociocultural space, is not only a highly competent designer, but a 'simple' user of things - of the production by professional design projecting. A designer through their professional activity promotes implementation of a useful object or thing in the everyday life, but eventually how to use the designer's proposal is for the user to decide particularly the user creates not only objective, but also spiritual and meaningful environment in the daily manipulation of things. Hence, design as construction, projection and creation of sociocultural reality acquires clear directions and stages corresponding the general structure of sociocultural activity - cognition and value comprehension of reality in the process of elaboration and projecting item form, realization of the found sociocultural meaning in the thing, decoding in the process of mastering sociocultural space, object surrounding.

The formation of professional thinking culture, purposeful development of person`s capacities is a significant factor of teaching students the fundamentals of graphic design [3]-[5].

We have distinguished the following key peculiarities of students' creative activity:

Peculiarities of aesthetic, design, artistically-graphic creative imagination and thinking, which provide selection of the main and the most essential image, ensure its concretization and generalization as well as original composition creation;

1) visual memory characteristics, contributing to creation of bright visual images and assisting in successful transformation of these images into artistic image;

2) emotional attitude (specially developed aesthetic feelings) towards perceived and depicted phenomenon;

3) Volition characteristics of an individual, providing practical realization of the artist's creative message.

Creative design process is impossible without the implementation of personal computer into the graphic design teaching process. On the basis of analyzed methodological we have revealed conditions that prove the appropriateness of information technologies usage in the learning process. Among them it is relevant to distinguish that the students' project-artistic training should correspond to rapidly changing demands of the industry.

Graphic design nowadays is becoming more and more integrating profession which combines both difficult multilevel objects of visual reality and methods of various professional subjects. Apart from visual image and space, graphic design covers such dimensions as movement, time, and interactivity and operates with different means of economic, marketing and cultural communication. In pedagogues' and psychologists' opinion, such as S. Novoselova, I. Belavina, N. Naumov, information and communication technologies are the most powerful methods of upbringing and developing in student various skills, namely creative skills. In this relation, these methods have obvious advantage over the rest traditional methods.

The development of interactive communication with 
computers - demonstrates a real switch into creative methods of image processing - through ergonomical colour rendering, graphic images design. Computer graphic arts give a lot of perspective in projecting, design and research activities.

As a result of ever-increasing growth of the Internet network the new area of information technologies emerged web design, one of the most developing systems, which allows to form special graphic information environment not only for artists, constructors, but for pedagogues too. The web-design capacities play special role in the development of students` creative activity and are a unique means of their professional preparation.

The preparation of specialists in the field of graphic design above all requires the establishment of creative tasks in accomplishing varied cognitive operations in practical activity. In connection with this such educational priorities were defined:

1) Ensuring inter-subjects connections, scientific context and depth of creative activity process headed for artistic, graphic, aesthetic and visual compositional projecting and modelling;

2) Developing creative thinking and ability to interconnect visual and logical moments in design activity;

3) Acquiring the arsenal of tools and methods to handle thematic tasks, learning and research work, artistic-visual, graphic, visual, aesthetic expressiveness in different forms of design-process activity.

\section{CONCLUSION}

In the article it is assumed that systematic and persistent striving of students to acquire and master skills of artistic-graphic and design activity will successfully influence the process of students aesthetic and artistic-graphic education, and its effectiveness depends on such factors: keenness and interest in personal creative, artistic-graphic practical design-activity; the implementation of various techniques and methods of artistic-graphic compositional decisions in the creative design process; the development of logical, constructive and artistic-visual creative imagination and thinking.

\section{ACKNOWLEDGMENT}

This article was in part supported by Prof. Salman who has read the manuscript and offered his valuable suggestions. A. Al Atabi is grateful to Prof. Inzhestoikova for her expert advice and criticism. Special thanks go to the students who were the inspiration of this research. We thank our families and friends for their moral support.

\section{REFERENCES}

[1] N. Postnikov, "Graphic design in the system of aesthetic and artistic education of teenage schoolchildren on the Lessons of Fine Art," Ph.D. dissertation, Moscow, Russia, 1995, pp. 244.

[2] J. Ladyhin, "Development of learners' creative abilities in the integrative actional field of fundamentals of design course," Ph.D. dissertation, Moscow, Russia, 2000, pp. 247.

[3] A. Batarshev, "Psychodiagnostics of communication capability, or how to define organizational and communicative qualities of personality," Moscow, Russia: Vlados, 1999, pp. 176.

[4] J. Korzinova, "Integrative tasks on technical graphics as means of developing creative abilities of the artistic department students," Moscow, Russia, 1992, pp. 16.

[5] V. Kuzin, Psychology: Textbook, 2nd ed. Moscow, Russia: Vyssha Shkola, 1982, pp. 256.

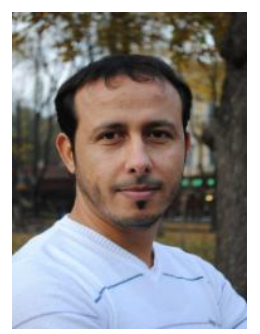

Ayad Hayawi Al Atabi was born on September 1, 1976 in Thi-Qar, Al Nasiriya, Iraq. He received his diploma of artist, Fine Art Institute, Painting Department, Thi-Qar, Iraq in1996. He received his bachelor of arts (plastic arts), Al-Basrah University, Painting Department, Basrah, Iraq in 2000. He received his master of arts, South Ukrainian State Pedagogical University, Graphic Art Department, Odessa, Ukraine in 2008. He received his Ph.D. (fine arts), South Ukrainian State Pedagogical University, Graphic Art Department, Odessa, Ukraine in 2012

He worked as a lecturer at the Graphic Art Department, South Ukrainian K.D. Ushynsky National Pedagogical University, Ukraine. He now works as a lecturer and as a designer at the Department of Journalism, Thi Qar University, Iraq. He also works as an artist, a sculptor, and a designer. His areas of research interests include graphic design; computer graphic design; painting; sculpture, art teaching methodology

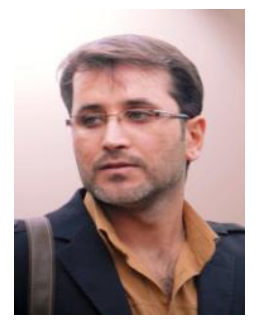

Luhaib Kamil Al Abboodi was born on July 27, 1976 in Thi-Qar, Al Nasiriya, Iraq. He received his diploma of artist, Fine Art Institute, he was with the department of Painting, Thi-Qar, Iraq in 1997. bachelor of arts (plastic arts), Al-Basrah University, Painting Department, Basrah, Iraq in 2010. He worked as a teacher of arts in a Secondary School, Al Nasiriya. He is now working as a general director of the School Department at Division of Fine Arts, Ministry of Education of Iraq, in Nasiriya, Iraq. He also works as an artist and a sculptor and he research interests include graphic design; computer graphic design; painting; art teaching methodology. 